\title{
Cobertura das mudanças climáticas: percepções de fontes de informação e jornalistas ${ }^{1}$
}

\author{
COVERAGE OF CLIMATE CHANGE: \\ PERCEPTIONS OF INFORMATION SOURCES \\ AND JOURNALISTS
}

\section{Eloisa Beling Loose}

Jornalista formada pela Universidade Federal de Santa Maria (UFSM), com mestrado em

Comunicação e Informação pela Universidade Federal do Rio Grande do Sul (UFRGS)

e doutora em Meio Ambiente e Desenvolvimento pela Universidade Federal do Paraná

(UFPR). Pesquisadora dedicada às problemáticas da interface entre jornalismo/comunicação

e meio ambiente.

E-mail: eloisa.beling@gmail.com

Recebido em 16 de outubro de 2016. Aprovado em 5 de abril de 2017.

\section{Resumo}

$\mathrm{O}$ artigo discute a cobertura sobre as mudanças climáticas a partir das percepções das fontes de informação e dos jornalistas da Gazeta do Povo. O texto aborda a produção noticiosa de um tema que abarca múltiplas escalas, incertezas e riscos pouco tangíveis para a população. Apresenta-se uma Análise de Conteúdo das entrevistas com os envolvidos nesta produção. Os resultados mostram que a necessidade de relações entre local e global e uma perspectiva preventiva são reconhecidas, embora a lógica jornalística e o perfil generalista dos jornalistas os induzam a escrever notícias mais pontuais.

Palavras-chave: Jornalistas. Fontes de informação. Mudanças climáticas.

1 A primeira versão deste trabalho foi apresentada no VII Encontro de Pesquisa em Comunicação (Enpecom), realizado em Curitiba no ano de 2015. O texto atual foi revisto e modificado, e é fruto de uma pesquisa de doutorado defendida em 2016. 


\section{Abstract}

The article discusses the coverage of climate change through the perceptions of the sources of information and journalists of Gazeta do Povo. This paper is about the news production process of a theme that encompasses multiple levels, uncertainties and non-tangible risks for the population. It presents a content analysis from interviews with those involved in this production.
The results show that the need for a relationship between local and global, and a preventive approach are recognized, although the journalistic logic and generalist profile of journalists induce them to write more specific news.

Keywords: Journalists. Information sources. Climate change.

\section{Introdução}

Produzir notícias a respeito de temas complexos é um desafio que se coloca para os jornalistas, mas não apenas para eles. Este trabalho centra-se na discussão das dificuldades percebidas por jornalistas e fontes de informação da Gazeta do Povo, jornal de maior circulação no Paraná, na cobertura das mudanças climáticas (doravante MC). É bastante comum encontrar discussões sobre a etapa da produção voltada para os dilemas e restrições das rotinas profissionais dos jornalistas, contudo, insere-se nesse contexto também o papel daqueles que são a origem das informações trabalhadas pelos profissionais da imprensa: as fontes.

Esta análise decorre de uma pesquisa de doutoramento sobre a relação entre comunicação, percepção ${ }^{1}$ e governança dos riscos climáticos no circuito da notícia do citado jornal. Neste texto foca-se nos apontamentos realizados por jornalistas e fontes de informação desse diário, que foram associados às notícias sobre o tema no segundo semestre de 2013. Após o mapeamento de quem eram os sujeitos envolvidos nesse processo, foram feitos os convites. Ao total, nove jornalistas e treze fontes de informação participaram da pesquisa, na qual foram realizadas entrevistas semiestruturadas ${ }^{2}$. As respostas foram, então, categorizadas, conforme a Análise de Conteúdo (AC).

Aqui traz-se um breve histórico de quando as MC passaram a ser pauta na mídia, já apresentando algumas barreiras intrínsecas a esse processo. A relação entre fontes de

1 O termo percepção, nesta pesquisa, está associado ao viés construcionista, no qual é visto como uma construção mental, em que o sujeito desempenha um papel ativo neste processo.

2 Todos os entrevistados desta pesquisa terão suas identidades preservadas a fim de manter o anonimato previsto na pesquisa. Jornalistas serão apresentados como J1, J2 .. e fontes de informação como F1, F2... 
informação e jornalistas também é evidenciada. Em seguida, foca-se nos riscos climáticos e no papel do jornalismo - como um dos atores mais importantes na sociedade contemporânea - na comunicação do tema. Por fim, sistematizam-se alguns dos desafios percebidos por jornalistas e fontes de informação na construção das notícias sobre o assunto em um jornal local/regional, e levantam-se considerações a partir dos resultados obtidos.

\section{Mudanças climáticas na imprensa}

As questões ambientais só começam a repercutir para além do âmbito da ciência nos anos 1970, quando há um crescimento da consciência ambiental, sobretudo na Europa e nos Estados Unidos, e a emergência da noção de uma crise ambiental. Tal compreensão revelou um estado explícito e generalizado de problemáticas (a exemplo das mudanças do clima) e, com isso, a necessidade de uma ação global para contê-las. Também assinala-se que os efeitos atribuídos às $\mathrm{MC}$ são amplificados e agravados em razão das vulnerabilidades socioambientais que se fazem presentes no mundo contemporâneo, especialmente nos países menos desenvolvidos.

É a partir dos anos 1980 que, de forma mais recorrente, as MC começam a fazer parte dos interesses dos jornalistas, quando os debates a respeito do tema se intensificaram e a opinião pública, especialmente nos Estados Unidos, começou a tomar conhecimento do que seria o aquecimento global ${ }^{3}$. Em 1988 houve a formação do Painel Intergovernamental das Mudanças Climáticas (IPCC, na sigla em inglês) e, no ano seguinte, a convocação da Conferência das Nações Unidas sobre Meio Ambiente e Desenvolvimento.

Porém, mesmo após a inserção da questão climática na esfera midiática, a partir desse período, a cobertura do tema não ocorreu de forma sistemática. Assim como outros temas ambientais (HANSEN, 2010), as MC passam por momentos cíclicos de visibilidade, dependentes de eventos e lançamentos de documentos para mobilizar sua cobertura em razão da necessidade de um gancho factual ou do valor-notícia vinculado ao novo.

Vale mencionar que a forma como esse tema é abordado é, muitas vezes, distante da realidade do leitor, o que contribui para o pouco envolvimento que as pessoas manifestam com a questão das MC (O'NEILL; NICHOLSON-COLE, 2009). O aspecto global das MC costuma ser pouco articulado com outras escalas geográficas. $\mathrm{O}$ fato de suas consequências estarem previstas para o futuro (e não para o presente) também colabora para que o tema seja algo distante do cotidiano do público.

3 Ainda que se saiba que o aquecimento global é apenas uma das facetas das MC, não é raro encontrar na imprensa esta expressão como sinônimo do todo. Em razão do limite de espaço e da não centralidade dessa discussão no artigo, aqui se ignoram as diferenças e implicações conceituais entre as duas expressões. 
A mediação realizada pelos meios de comunicação social é de extrema relevância para que o trabalho científico e as decisões sociopolíticas tornem-se públicas. Carvalho et al. (2011b, p. 105) reforçam isso quando afirmam que "os media são actores centrais na formulação, reprodução e transformação do significado deste problema complexo e uma arena fundamental para a legitimação e/ou crítica de opções políticas e económicas". Boykoff (2011) atenta ainda que as representações da mídia sobre a ciência e política do clima não conduzem linearmente a opinião pública a uma mudança individual ou social, mas têm provado que são, entre outros fatores, um dos elementos-chave que tem costurado a ciência, a governança e o cotidiano das pessoas sobre a questão climática.

Também a forma de comunicar os riscos ganha relevo, especialmente quando é pelo viés dos efeitos negativos das MC que grande parte das notícias do tema é elaborada, como demonstra o estudo de Painter (2013), no qual jornalistas dizem achar que a abordagem por meio dos riscos é mais atrativa do que através das incertezas. Destaca-se que enquadrar o tema a partir dos riscos não significa, automaticamente, que a imprensa está sendo sensacionalista ou alarmista. A opção por algo que alerte o público pode ser uma forma de atraí-lo para uma melhor contextualização do fenômeno e discussão de formas para enfrentar seus riscos.

\section{Fontes e jornalistas: meandros dessa relação}

O processo jornalístico é derivado de um trabalho de interpretação e ressignificação de sentidos feito pelos jornalistas que, na sua rotina diária de trabalho, junto com as fontes de informação, escolhem quais os assuntos e enfoques terão visibilidade na esfera pública. As escolhas, todavia, não são aleatórias; ao contrário, os jornalistas constroem as notícias a partir de uma série de valores e técnicas da cultura jornalística, das rotinas, orientações e constrangimentos da organização na qual está inserido, das trocas provenientes do contato com as fontes de informação e do próprio conhecimento que têm sobre o tema. Portanto, a constituição da notícia revela-se complexa, com diferentes interesses e objetivos que se sobrepõem (das fontes consultadas, da empresa, do jornalista que apura e escreve o texto, do editor que o corta e modifica, daquele que propôs a pauta, do possível público-alvo etc.).

O relacionamento com as fontes de informação é, dessa forma, mais uma dimensão importante na etapa de produção da notícia. Schmitz (2011) salienta que o saber do jornalismo depende da interação com a fonte. Visto por muitos autores como um elo fundamental tanto no fabrico das notícias quanto nos estudos sobre profissionalismo (ALSINA, 2009; SOUSA PINTO; 2009), os sujeitos que serão escolhidos como fontes 
de consulta dos jornalistas são aqueles que introduzirão novas informações e sentidos nas notícias. Ainda que os jornalistas procurem fontes para ratificar algo que já esperavam, toda entrevista consiste em uma interação, em uma negociação de sentidos que também implica a representação de papéis sociais e o prestígio ou depreciação de aparecer ou não no jornal.

Desde o início da carreira, os jornalistas aprendem que precisam cultivar boas fontes, pois, geralmente, são elas que possibilitam a publicação de um acontecimento inédito, que pode render uma boa reportagem aos profissionais. Não obstante, essa tarefa é delicada, exige confiança, tempo e disponibilidade. É preciso entender que a fonte de informação procurada aceita atender o jornalista por alguma razão (porque tem responsabilidades públicas, interesses institucionais ou pessoais). Responder aos jornalistas, como eles querem e precisam, exige das fontes atenção e tempo.

De outro lado, os jornalistas também dependem das fontes de informação para construir seus relatos com efeitos de verdade e realidade. A credibilidade do jornalismo está associada ao espaço dado às fontes com reputação na sua área. Quando alguém com dever público ou alvo de uma polêmica se recusa a falar com a imprensa, essa informação é posta na matéria e constrói-se um sentido negativo, de que aquele indivíduo tem algo a esconder.

Alsina (2009) traz algumas estratégias utilizadas por fontes para obter influência sobre os jornalistas, como a punição e o prêmio. As relações estabelecidas entre jornalistas e fontes envolvem a restrição a determinadas informações e a criação de um sentimento de dívida em relação à fonte por algum dado importante ou mesmo por convites especiais, o que representa aspectos que demonstram a tentativa de domínio das fontes sobre os jornalistas. Jornalistas também utilizam o prestígio de sua empresa e podem apelar até para o suborno por causa de uma informação.

A descontextualização das respostas, um problema ético, pode distorcer a afirmação e, além de minar a relação com a fonte, pode desencadear processos judiciais contra o jornal e o jornalista. Essas são situações que exemplificam o quão delicado pode ser o relacionamento desses dois grupos sociais. Pode existir a cooperação e a interdependência, entretanto nem sempre é assim; e o bom relacionamento vai depender de uma postura profissional de ambos.

Sendo assim, o jornalismo cotidiano é fabricado sob negociação constante (e nem sempre pacífica) dos atores concentrados na etapa inicial do circuito (jornalistas e fontes), porém torna-se acabado somente com o ato de interpretação dos leitores.

As implicações dessa relação abrangem uma série de subjetividades que também estarão presentes no âmbito do discurso. Não apenas quando o jornalista decide quem 
procurar para entrevistar, mas também quais perguntas faz, o que seleciona das respostas para construir o texto e o que avalia que será mais relevante deixar como citação direta. Todavia, não é apenas a escolha das fontes ou das questões feitas a elas que explicam o porquê de as notícias serem como são. Nas três fases do processo informativo - coleta, seleção e apresentação das notícias (WOLF, 1995) -, o jornalista e seu contexto de produção interferem no que o público saberá ou não a respeito de dado fato e também o que foi acontecimento ou não naquele dia.

\section{O papel do jornalismo na comunicação de riscos}

Segundo Beck (2010), a comunicação de massa é um aspecto central para tornar os riscos da sociedade contemporânea em uma questão que possa ser discutida para tentar ser incluída na agenda política. Para tanto, a comunicação, além de jornalistas, precisa de fontes de informação que expressem pontos de vista, dados e argumentos a fim de construir os discursos e disseminá-los ao público. No caso das MC e seus riscos, tais fontes costumam ser oriundas do campo científico. Um estudo anterior realizado com as notícias da Gazeta do Povo (LOOSE; LIMA; CARVALHO, 2014) evidenciou que elas são fruto, em sua maior parte, da divulgação de pesquisas e/ou que suas fontes são oriundas do campo da ciência, dando ênfase às preocupações típicas desse lugar de fala. Sendo assim, não é de surpreender que grande parte das fontes de informação consultadas seja formada por cientistas ou profissionais com formação acadêmica.

A invisibilidade do processo da mudança do clima, assim como as inúmeras incertezas que impedem correlações simplificadas entre determinado evento extremo e o processo mais amplo do fenômeno requer que os sujeitos formulem e visibilizem seus diferentes aspectos. É nessa linha de raciocínio que as dificuldades percebidas por fontes de informação e jornalistas precisam ser conhecidas e superadas.

O jornalismo é entendido aqui dentro do âmbito da comunicação de riscos, entendida como "o processo de troca entre a comunidade acadêmica, os profissionais das agências reguladoras, os grupos de interesse e o público em geral, em que se considera como melhor avaliar e gerenciar os riscos" (POWELL; LEISS, 2005, p. 192), logo, independe dos meios de comunicação. De forma geral, a imprensa amplifica o alcance das informações, convocando o público para contribuir com o enfrentamento ou apenas informando sobre as medidas que estão sendo tomadas. É nesse sentido que são compreendidas as potencialidades da Gazeta do Povo no contexto da comunicação de riscos climáticos.

Tal processo envolve o entendimento das dinâmicas correlacionadas ao risco e não mero convencimento de um grupo (causador ou responsável pelo risco) para outro (o de 
vítimas do risco). Nesse sentido, a regularidade e boa contextualização das notícias sobre o tema se tornam aspectos prioritários. Por ser um assunto complexo, com cruzamento de vários interesses (científico, político, econômico e social), e dominado pelas fontes científicas, já temos um quadro com fatores delicados que requerem um bom domínio sobre suas causas e efeitos. Entretanto, para além de um tema ambiental (que pode ter atributos idênticos), as MC possuem uma abrangência multiescalar e um tempo futuro, baseado em projeções, o que é de difícil representação e aproximação do público.

Aliado a isso, tem-se que os riscos climáticos são invisíveis (quando percebemos sua manifestação eles já se tornaram catástrofes; passaram da fase em que eram riscos e tornaram-se acontecimentos concretos), assim como sua causa primária, a emissão de gases de efeito estufa (GEE) que, além de não ser visível, não tem relação direta ou imediata com a saúde ou o entorno (MOSER, 2010). Tais características podem ser vistas como desafios à uma efetiva comunicação do problema, primeiro passo para mobilizar os cidadãos para seu enfrentamento.

Pelo viés do jornalismo, a busca pelo novo e pela novidade interfere de forma crucial nesse processo. Como pautar as MC se elas estão presentes constantemente no nosso dia a dia? Como trazer a novidade de um problema já identificado pelos cientistas há anos? De que maneira mobilizar elementos novos de um fenômeno que se acelera silenciosamente? Se a imprensa já informou uma vez, é necessário um aspecto inédito ou diferente para trazer o assunto novamente para o jornal, o que evidencia o descompasso existente entre a necessidade de informar sistematicamente o público e as lógicas do jornalismo.

A aparente falta de opções para atrair o público e satisfazer os critérios de seleção das notícias dá pistas de o porquê o discurso dos riscos aparece repetidas vezes: são essas as imagens que, em geral, permitem que o tema se torne pauta e ganhe espaço no jornal. A cada risco que se transforma em tragédia, o jornalismo consegue um "gancho", um aspecto recente que se encaixa nos atributos de noticiabilidade, para então (re)construir a história das MC. Os eventos políticos e a divulgação de relatórios sobre o tema costumam servir a esse propósito também. A cada reunião da Conferência das Partes (COP), expectativas diferentes alimentam o encontro de chefes de estado, permitindo que o que foi discutido tenha algum espaço na agenda midiática.

Os jornalistas esperam eventos "reais" porque sua prática fundamenta-se no acontecimento e não na previsão dele. A não existência de uma manifestação concreta pode ser vista como especulação pela comunidade interpretativa, pois jornalistas não costumam trabalhar com projeções - e sim com fatos. De acordo com Kitzinger e Reilly (2002, p. 40), os veículos de comunicação atuam melhor "na notícia retrospectiva do que na 
notícia prospectiva sobre o risco, e as notícias retrospectivas sobre o risco são naturalmente reduzidas".

O conjunto dos acontecimentos de cada dia, a linha editorial, os recursos humanos disponíveis e outros fatores organizacionais também determinam o que será ou não publicado por cada jornal. Um jornalista que não domina o assunto terá mais dificuldades e, possivelmente, construirá uma notícia com mais lacunas do que um especializado. A divulgação da pesquisa será feita, mas sua problematização contextual será reduzida ou ignorada porque a dinâmica da redação e a ausência de conhecimentos prévios limitarão o trabalho do jornalista.

A especialização em ciência e/ou meio ambiente no meio jornalístico é, do ponto de vista social, uma forma de proporcionar acesso de qualidade ao conhecimento científico a um grande público, o que não costuma acontecer de outra maneira. Já do ponto de vista econômico, os profissionais especializados oneram as empresas, já que as redações estão cada vez mais enxutas e requerem profissionais generalistas e multiplataforma, como ciência e meio ambiente são áreas de pouca audiência, se comparadas a esportes, política e economia, por exemplo, os jornalistas dessas áreas são logo suprimidos.

Os critérios de noticiabilidade - como preferência pela novidade, proximidade e ameaça - delimitam um certo olhar para os fatos. Pidgeon (2012 apud ASHE, 2013), que trabalha com a cobertura das $\mathrm{MC}$, listou mais alguns elementos que tendem a atrair a atenção dos jornalistas nas histórias de risco: questões que envolvem responsabilização ou culpa; histórias de interesse humano, relacionadas a assuntos ou pessoas de grande destaque, com forte impacto visual, relacionadas com sexo ou crime, com exposição de muitas pessoas, que envolvem um evento que pode sinalizar uma tendência mais ampla e que possuem segredos e acobertamentos- aspectos que possuem valor de notícia, estimulam o interesse do público e se tornam o gatilho para que um acontecimento (e não outro) seja publicado no jornal. Ashe (2013) lembra que tais critérios, ainda que reconhecidos pela comunidade interpretativa dos jornalistas, variam de profissional para profissional, de editor para editor, de veículo para veículo, afinal dependem de julgamentos subjetivos, dependentes das práticas institucionais aprendidas e da preconcepção que os produtores têm acerca dos interesses de sua audiência.

\section{As percepções de jornalistas e fontes de informação}

Apresentam-se aqui as análises das entrevistas feitas com jornalistas e fontes de informação sobre os desafios para o melhor alcance da comunicação de riscos via notícias. As entrevistas foram feitas por Skype ou presencialmente, quando possível, sendo 
gravadas e depois transcritas. A partir de uma categorização, feita por meio dos procedimentos da Análise de Conteúdo proposta por Bardin (2014), destacaram-se os principais aspectos envolvidos na construção da notícia e na percepção de como esses dois grupos de atores sociais veem a imprensa.

A análise, de cunho qualitativo, se deu a partir de uma comparação sistemática das respostas, buscando captar elementos que apontassem para os obstáculos encontrados nesse meio de comunicação. As categorias construídas e apresentadas neste texto são: relação global versus local, formação especializada do jornalista e enquadramento dos riscos.

\section{Relação global versus local}

Em Portugal, Carvalho (2011a) constatou que o cenário internacional recebe mais atenção que as instâncias locais, estas últimas são aquelas que justamente aproximariam a população com o tema. Segundo a autora (2011a, p. 236), "no discurso mediático, a acção sobre as alterações climáticas é essencialmente associada ao locus global, das cimeiras políticas intergovernamentais, não estando ao alcance dos cidadãos", o que, consequentemente, não relaciona os hábitos e posturas da população em relação ao problema. A conexão do local com o global é fundamental para se pensar em outras atitudes e o jornalismo, como campo de excelência de medição e legitimação de discursos, precisa estar atento às formas com que dissemina a questão. Ainda mais quando pesquisas apontam que os cidadãos acessam compreensões sobre ciência - e o tema MC está geralmente colocado dentro deste escopo - majoritariamente pela cobertura dos meios de comunicação (ANTILLA, 2010).

Nas entrevistas realizadas com jornalistas, foi perguntado se eles consideravam o tema das $\mathrm{MC}$ um assunto local em Curitiba, e as respostas apontaram que não há consenso. J1, J6 e J9 responderam que em qualquer lugar do planeta já se pode sentir os efeitos do fenômeno, inclusive em Curitiba, como quando há dias quentes no inverno, por exemplo. Já J3, J4, J7 e J8 acreditam que o assunto está muito mais no âmbito internacional, com enfoque global, sendo o link local-global algo que precisa ser melhor trabalhado. Dois deles até mencionaram que, por Curitiba ser tipicamente uma cidade fria, é difícil saber se as pessoas conseguem relacionar o tema com o cotidiano ou, de outro modo, se nesta cidade o efeito local não é tão sensível. A falta de certeza em afirmar que dado evento climático é fruto realmente das MC também dificulta essa construção.

J5 disse que o tema pode virar uma pauta local em razão de alguma iniciativa em relação às emissões, por exemplo. Entretanto, no ano de 2013, esse tipo de pauta não foi aquela que recebeu atenção, sendo a disseminação de pesquisa e relatórios os grandes gatilhos para a produção de notícias sobre MC, como ratificado em análise anterior (LOOSE; LIMA; CARVALHO, 2014). 
Como as fontes de informação, em sua maioria, não eram locais, limitou-se a perguntar para as poucas restantes, pois estas acreditavam que o jornal em questão não procurava mais informações em nível local. Uma delas (F1) respondeu:

É porque o cara [o jornalista] quer uma personalidade. A gente tem gente aqui a universidade pesquisando vários desses assuntos que são fontes interessantes [...]; a gente tem vários pesquisadores aqui, de ONGs, de universidades, da Embrapa, que estão nesses projetos e estão aqui em Curitiba, boa parte deles...

O fato das fontes de informação sobre o tema não serem locais está associado a origem da maioria das publicações: as agências de notícias. De um total de 72 notícias encontradas por meio de palavras-chave no buscador do jornal, 57 delas representam material oriundo de agências, totalizando $79 \%$ da amostra. Esse "hábito" de trazer a questão das MC pela perspectiva de outros afasta o fenômeno do local/regional e ignora as fontes de informação que estudam e vivenciam as alterações do clima em escalas próximas ao leitor.

A relação entre global e local também foi posta como papel da imprensa, no sentido de contribuir para o envolvimento da população:

F12 - O papel da mídia é importantíssimo porque a mídia pode tanto trazer uma visão das MC como algo distante e que não vai nos afetar diretamente [...] mas, ao mesmo tempo, ela pode sim demonstrar importância do papel do cidadão no contexto local. [...] eu acho que esse é o papel mais importante, na verdade; não apenas mostrar internacionalmente o que está se fazendo esforço, mas qual a importância da relação local do cidadão em relação às $M C$, nas menores coisas, diminuição de consumo, uso consciente do automóvel e aí por diante.

Aos jornalistas também foi perguntado por que poucas fontes locais eram consultadas, o que gerou respostas bastantes diferentes. J1 e J8 disseram que não poderiam se restringir a Curitiba, o que poderia incorrer na perda de diversidade de opiniões; já J4 afirmou que a maioria de suas fontes é do Paraná e que as entrevistas são facilitadas quando as fontes conhecem o jornal (algo que, pelo próprio alcance do veículo, ocorre predominantemente em âmbito estadual): "não precisa apresentar o jornal, só se apresenta e faz a pessoa lembrar de você". J6 também mencionou uma preferência por fontes locais em razão do jornal ser regional. Estas visões, divergentes, não se refletem nos produtos (as notícias sobre MC) analisados: pode-se dizer que falta tanto o aspecto local quanto a diversidade colocada como justificativa para não trazer mais fontes conhecedoras da realidade do estado 
(muitos estudos divulgados pelas agências e republicados na Gazeta do Povo trazem como fontes apenas os pesquisadores que desenvolveram a investigação, sem contrapontos).

$\mathrm{J} 4$ e J5 comentaram que com o advento da internet o acesso às fontes (de qualquer lugar) já não é um problema. De um modo geral, as tecnologias permitiram que mesmo jornais menores tivessem acesso às fontes do eixo Rio-São Paulo e até do exterior do Brasil. J5 explicita essa questão:

há quase uma década era mais dificil de encontrar fontes, principalmente fontes locais. Agora a gente até tem algumas fontes daqui que fazem parte de algumas partes do relatório do IPCC e a gente já tem uma ideia de quais são os centros de excelência em estudo de clima no Brasil. Acesso a fontes fora do país para um jornal médio já não é tão simples, a gente tem que contar mais com fontes nacionais, aqui do Brasil. Mas o acesso a fontes não é o grande problema.

Essa oportunidade de acesso, apesar da distância, expande as possibilidades do jornalista, que nem sempre percebe essa carência do aspecto local. O fato de os jornalistas hoje realizarem seu trabalho sem sair necessariamente da redação (o repórter não circula mais pela cidade como no passado em razão de custos, tempo maior gasto na locomoção em razão do trânsito, necessidade de acompanhar a concorrência on-line etc.) também contribui para a diluição dessas amarras com o que é ou não problema local.

\section{Formação especializada do jornalista}

Embora alguns jornalistas tenham citado o cuidado de se tornar especialista em um só tema (em razão da proximidade com as fontes), todos percebem que aquele profissional que já entende as nuances do assunto e possui domínio da linguagem técnica apresenta vantagens no aprofundamento e também na rapidez com a qual elabora a notícia. J5 afirmou que existe uma dificuldade em razão da complexidade do tema:

o grande problema é a formação do jornalista pra lidar com o assunto, que é de um grau de complexidade alta. Como ele não aparece todos os dias no jornal, o jornalista que vai lidar uma vez, de vez em quando com o assunto, vai ter dificuldade de entender os critérios dos relatórios do IPCC, as margens que eles usam, os cenários que eles usam, porque que um cenário é diferente do outro.

A falta de profissionais com formação especializada repercute, muitas vezes, na superficialidade da notícia ou na ausência de abordagens novas, que fujam da obviedade dos lançamentos de relatórios científicos ou ocorrência das COP. Esse distanciamento de 
um tema dificulta que novas sugestões, enfoques e questionamentos apareçam na produção jornalística, o que resulta em matérias "sempre iguais", como identificado por J7: "a gente sempre estava dizendo a mesma coisa, tentando fazer isso de forma diferente, mas nem sempre isso é possível... Talvez a maior dificuldade fosse encontrar abordagens novas que despertassem o interesse do leitor neste assunto”.

Capta-se então uma preocupação por parte dos jornalistas em fazer notícias que atraiam o leitor, porém é difícil encontrar novas soluções quando o assunto é pautado de forma eventual - e não recorrente. Nota-se um desconhecimento de alguns profissionais da imprensa em relação às questões do clima, e também um desinteresse, afinal ainda não parece ser óbvio que esse fenômeno esteja associado com economia, política, saúde, meio ambiente, já que o tema no jornal em análise está, geralmente, associado ao campo científico. Uma das fontes (F4) reiterou essa percepção, associando a perspectiva integrativa dos temas à especialização: "Muitos acham que a mudança do clima é um problema ambiental [...], mas nós entendemos que ela [...] traz um debate econômico, na verdade um debate sobre desenvolvimento".

No trecho acima a fonte entrevistada destaca que a especialização necessária não é somente sob o aspecto restrito do que é ambiental, mas é preciso compreender o alcance das MC nos diferentes setores da sociedade. Ressalta-se que a compreensão da especialização ambiental adotada pela autora é ampla, abarcando a conexão entre diferentes saberes.

Quando perguntamos às fontes se sentem diferença no resultado final, quando entrevistados por especialistas, todos mencionaram que o trabalho se torna mais fácil e interessante, pois não precisam explicar noções básicas de ciência, por exemplo. Vários entrevistados avaliaram que houve uma melhora da cobertura em relação aos últimos dez anos (mesmo que em torno de picos), porém há uma preocupação em relação ao fim de espaços tradicionais de ciência e meio ambiente, com a consequente demissão de profissionais com experiência nessa área. Algumas fontes assinalam que falta capacitação aos jornalistas, e que há pouco investimento na formação desses profissionais.

\section{Enquadramento dos riscos}

Os enquadramentos dos riscos foram os mais recorrentes, ou seja, os efeitos das MC são mais frequentemente abordados que aspectos de prevenção, mitigação e adaptação aos riscos. J1 afirmou que os efeitos "são muito mais visíveis do que a prevenção, e no meio jornalístico a gente tem esse mal, né, de estar com coisas mais palpáveis”. Este jornalista disse que não há como escapar das notícias atreladas às tragédias, associadas aos critérios de noticiabilidade da negatividade, do impacto. Já as notícias sobre prevenção, para ele, exigem mais conhecimento sobre o tema para fazer as relações necessárias. 
Aqui fica claro que há uma dificuldade por parte dos jornalistas em trabalhar com acontecimentos que não sejam imediatos ou concretos. A lógica jornalística, calcada na factualidade, impede que matérias voltadas mais à interpretação da realidade em seus múltiplos aspectos, com maior contextualização e informações sobre prevenção, tenham espaço. Contudo, os riscos climáticos podem ser enfrentados a partir da disseminação de soluções e demais medidas que possam ajudar na minimização da emissão de GEE, por exemplo.

Assim como os jornalistas, as fontes de informação percebem que o tema emerge na pauta da mídia a partir de catástrofes e desastres ambientais, ou eventos, como a divulgação de relatórios do IPCC, nos quais as previsões dos efeitos são colocadas em evidência. O que pontuam é que, embora percebam algumas lógicas jornalísticas e a necessidade de "vender jornal", poderiam usar chamadas como oportunidades para melhor informar os públicos.

As fontes de informação atribuem um papel de extrema relevância à imprensa, já que é ela "que vai conseguir levar esse tema pra sociedade" (F1). Para tanto indicam que é preciso qualificar o debate das MC.

\section{Considerações finais}

A análise exposta mostra que, embora em situações diferentes, jornalistas e fontes de informação concordam, ao menos em parte, que é preciso ampliar o esforço na construção da relação local-global. Ainda que nem todos os jornalistas entrevistados percebam as MC como uma questão local em Curitiba (e no estado do Paraná) - até mesmo pela dificuldade de percepção sensorial do fenômeno -, há um reconhecimento da importância de aproximar o tema da população, até mesmo para atrair a atenção do público.

Também há uma forte concordância de ambos os grupos que a especialização, seja em termos de formação, seja em experiência por tempo de cobertura, tende a melhorar a qualidade das notícias produzidas. Nesse aspecto, as empresas jornalísticas são chamadas a rever o propósito de sua produção, que precisa apresentar mais do que a internet oferece em tempo real. A escolha por notícias mais contextualizadas, que oferecem subsídios consistentes e explicitam as conexões nem sempre óbvias das temáticas, é um diferencial importante para a promoção de um debate qualificado e, talvez, uma saída para a sobrevivência econômica dos impressos - que precisam se reinventar e não apenas republicar material que já estava disponível na internet no dia anterior, como ocorre, muitas vezes, com as notícias oriundas de agências (quase $80 \%$ das notícias sobre MC encontradas no jornal em estudo).

Em relação aos enquadramentos de riscos, ambos os grupos percebem de forma clara os critérios de noticiabilidade que imperam e trazem a história das MC novamente para os jornais. Ainda que a lógica jornalística se movimente em razão da factualidade e demais 
valores associados à captura do leitor, a reivindicação encontrada nas falas das fontes é que o enquadramento dos riscos seja visto como oportunidade para aprofundar a discussão, e não apenas relatar os fatos do dia. Sabe-se da dificuldade de trazer aspectos preventivos e não concretos para a elaboração da notícia, mas, por outro lado, confia-se que, pela amplificação possibilitada pela articulação da imprensa, tal superação pode ser fundamental para o envolvimento e mobilização dos cidadãos para o enfrentamento dos riscos climáticos.

De um modo geral, nota-se que as fontes de informação creditam um papel de grande importância à imprensa, ainda que enxergue limitações próprias de seus modos de fazer. Os jornalistas, por sua vez, consideram o papel social da imprensa, mas relativizam sua influência, como um dentre outros fatores. Em relação à cobertura das $\mathrm{MC}$, demonstram dificuldades em tornar o assunto mais chamativo e não apenas "falar mais do mesmo", em propor abordagens desvinculadas dos lançamentos de relatórios científicos ou da realização das COP, e trazer elementos preventivos. A falta de especialização (no caso, conhecimento aprofundado) dos jornalistas os conduz para a proposição de outras pautas e as agências de notícias se tornam, assim, um caminho barato para suprir a demanda ou interesse pelo assunto.

Ainda que fontes de informação e jornalistas possuam lógicas de produção diferentes, nota-se uma concordância no que diz respeito à necessidade de melhor informar os leitores sobre as $\mathrm{MC}$ e ao papel que poderia desencadear um veículo de comunicação em relação ao enfrentamento dos riscos climáticos. Contudo, tal reflexão coloca-se ao lado do entendimento de que os jornais são também empresas, que visam lucro, e possuem outros objetivos, que, muitas vezes, estão em disputa com o interesse público.

Os desafios que são apontados pelos jornalistas e fontes de informação entrevistados demonstram que para a Gazeta do Povo participar efetivamente da comunicação dos riscos climáticos em âmbito local, mais do que amplificar a visibilidade de aspectos globais e nacionais, por meio da edição de conteúdo de agências, será preciso investir em novos enquadramentos que aproximem os cidadãos das causas e soluções associadas às MC. Para qualificar o debate sobre as MC, seus riscos e formas de enfrentá-las, uma articulação entre melhor formação, cobertura mais sistemática e conhecimento sobre as interferências na realidade local precisam predominar o tipo de cobertura do jornal, invertendo o panorama detectado.

\section{Referências}

ALSINA, M. R. A construção da notícia. Petrópolis: Vozes, 2009.

ANTILLA, L. Self-censorship and science: a geographical review of media coverage of climate tipping points. Public Understanding of Science, Thousand Oaks, v. 19, n. 2, p. 240-256, 2010. Disponível em: <https://goo.gl/p16M54>. Acesso em: 2 ago. 2017. 
ASHE, T. How the media report scientific risk and uncertainty: a review of the literature. Oxford: University of Oxford, 2013. Disponível em: <https://goo.gl/SbmGAo>. Acesso em: 2 ago. 2017.

BARDIN, L. Análise de conteúdo. Lisboa: Edições 70, 2014.

BECK, U. Sociedade de risco: rumo a uma outra modernidade. São Paulo: Editora 34, 2010.

BOYKOFF, M. T. Who speaks for the climate? Making sense of media reporting on climate change. Cambridge: Cambridge University Press, 2011.

CARVALHO, A. (Org.). As alterações climáticas, os media e os cidadãos. Coimbra: Grácio Editor, 2011a.

CARVAlHO, A. et al. A reconstrução mediática das alterações climáticas. In: CARVALHO, A. (Org.). As alterações climáticas, os media e os cidadãos. Coimbra: Grácio, 2011b. p. 105-144.

HANSEN, A. Environment, media and communication. London: Routledge, 2010.

KITZINGER, J.; REILLY, J. Ascensão e queda de notícias de risco. Coimbra: Minerva, 2002.

LOOSE, E.; LIMA, M. D. V.; CARVALHO, A. Estudo dos enquadramentos sobre mudanças climáticas no jornal brasileiro Gazeta do Povo. In: PINTO-COELHO, Z.; ZAGALO, N. (Orgs.). Comunicação e cultura. Braga: Centro de Estudos de Comunicação e Sociedade, 2014. p.139-156.

MOSER, S. C. Communicating climate change: history, challenges, process and future directions. WIREs Climate Change, Hoboken, v. 1, n. 1, p. 31-53, 2010. Disponível em: <http://bit.ly/2pDxaL1>. Acesso em: 2 ago. 2017.

O’NEILL, S.; NICHOLSON-COLE, S. "Fear won't do it": promoting positive engagement with climate change through visual and iconic representations. Science Communication, Thousand Oaks, v. 30, n. 3, p. 355-379, 2009. Disponível em: <https://goo.gl/6cGkr7>. Acesso em: 2 ago. 2017.

PAINEL BRASILEIRO DE MUDANÇAS CLIMÁTICAS. Sumário executivo: impactos, vulnerabilidades e adaptação. Contribuição do grupo de trabalho 2 ao primeiro relatório de avaliação nacional do Painel Brasileiro de Mudanças Climáticas. Brasília, DF: PBMC, 2013. Disponível em: <https:// goo.gl/9XoTr8>. Acesso em: 16 nov. 2017.

PAINTER, J. Climate change in the media: reporting risk and uncertainty. London; New York: I. B. Tauris; Reuters Institute for the Study of Journalism, 2013.

POWELL, D.; LEISS, W. Um diagnóstico das falhas de comunicação sobre riscos. In: MASSARANI, L.; TURNEY, J.; MOREIRA, I. C. (Orgs.). Terra Incógnita: a interface entre ciência e público. Rio de Janeiro: Fiocruz, 2005. p. 183-201.

SCHMITZ, A. A. Fontes de notícias: ações e estratégias das fontes no jornalismo. Florianópolis: Combook, 2011.

SOUSA PINTO, A. E. Jornalismo diário: reflexões, recomendações, dicas e exercícios. São Paulo: Publifolha, 2009.

WOLF, M. Teorias da comunicação. 4. ed. Lisboa: Presença, 1995. 